\title{
Intramuscular myxoma in the gluteus maximus muscle after continuous intramuscular injections
}

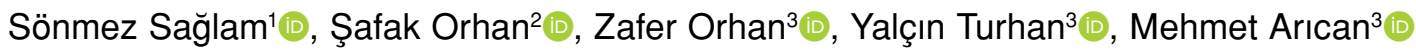 \\ ${ }^{1}$ Department of Orthopedics and Traumatology, Health Sciences University, Gülhane Training and Research Hospital, Ankara, Turkey \\ ${ }^{2}$ Student, Demiroglu Science University, Medical School, Istanbul, Turkey \\ ${ }^{3}$ Department of Orthopedics and Traumatology, Düzce University Faculty of Medicine, Düzce, Turkey
}

Intramuscular myxoma is a rare, benign neoplasm of mesenchymal origin, affecting the musculoskeletal system. The incidence rate of intramuscular myxoma varies from 0.1 to 0.3 cases per 100,000 individuals. ${ }^{[1]}$ The age at presentation is 40 to 70 years. About $66 \%$ of the cases are female. ${ }^{[2]}$ The most frequent locations of intramuscular myxoma are the muscles of the thigh, buttock, shoulder, lower leg, and upper arm. ${ }^{[3]}$ Imaging techniques are helpful; however, the correct diagnosis can be made only on histological examination. ${ }^{[4]}$ Surgical excision is curative and recurrence is rare. Herein, we present a rare case of intramuscular myxoma occurring after continuous intramuscular injections to the same region.
Received: October 19, 2021

Accepted: December 18, 2021

Published online: December 22, 2021

Correspondence: Sönmez Sağlam, MD. Sağlık Bilimleri Üniversitesi Gülhane Eğitim ve Araştırma Hastanesi Ortopedi ve Travmatoloji Kliniği, 06010 Keçiören, Ankara, Türkiye.

E-mail: dr.sonmezsaglam@gmail.com

Doi: $10.52312 /$ jdrscr.2022.9

Citation: Sağlam S, Orhan Ş, Orhan Z, Turhan Y, Arıcan M. Intramuscular myxoma in the gluteus maximus muscle after continuous intramuscular injections. Jt Dis Relat Surg Case Rep 2022;1(1):31-34

(02022 All right reserved by the Turkish Joint Diseases Foundation

This is an open access article under the terms of the Creative Commons Attribution-NonCommercial License, which permits use, distribution and reproduction in any medium, provided the original work is properly cited and is not used for commercial purposes (http://creativecommons. org/licenses/by-nc/4.0/).

https://www.casereportsjointdrs.org

\section{ABSTRACT}

Intramuscular myxoma is a rare, benign neoplasm of mesenchymal origin, affecting the musculoskeletal system. It usually develops after trauma. Herein, we report a rare case of an intramuscular myxoma which was located in the musculus gluteus maximus due to continuous intramuscular injections to the same buttock every 21 days for seven years. A 61-year-old male patient presented with progressive buttock pain with a two-year onset which worsened in the last three months. On magnetic resonance imaging, a well-circumscribed, septated, cystic mass was detected. The lesion was removed completely. Pathological examination revealed the diagnosis of intramuscular myxoma. After the excision, the patient was relieved of pain, and there was no recurrence at one-year postoperatively. In conclusion, continuous intramuscular injections may lead to development of intramuscular myxoma, similar to trauma etiology. Marginal resection of the mass can be curative in selected cases.

Keywords: Gluteus maximus, intramuscular injection, intramuscular myxoma.

\section{CASE REPORT}

A 61-year-old male patient presented with progressive right buttock pain which started two years ago and increased for the last three months. He had a slowly growing, painful mass of the right buttock for two years. Pain increased while walking and lying on the right side. His medical history revealed intramuscular injections for male hypogonadism every 21 days at the same buttock for seven years before the onset of the mass. He did not have any other medical history. On physical examination, the lesion was found to be $6 \times 4 \mathrm{~cm}$ in size, firm, mobile and painful. There was no apparent pathology on the radiographs. Magnetic resonance imaging (MRI) examination was performed for a detailed evaluation of soft 

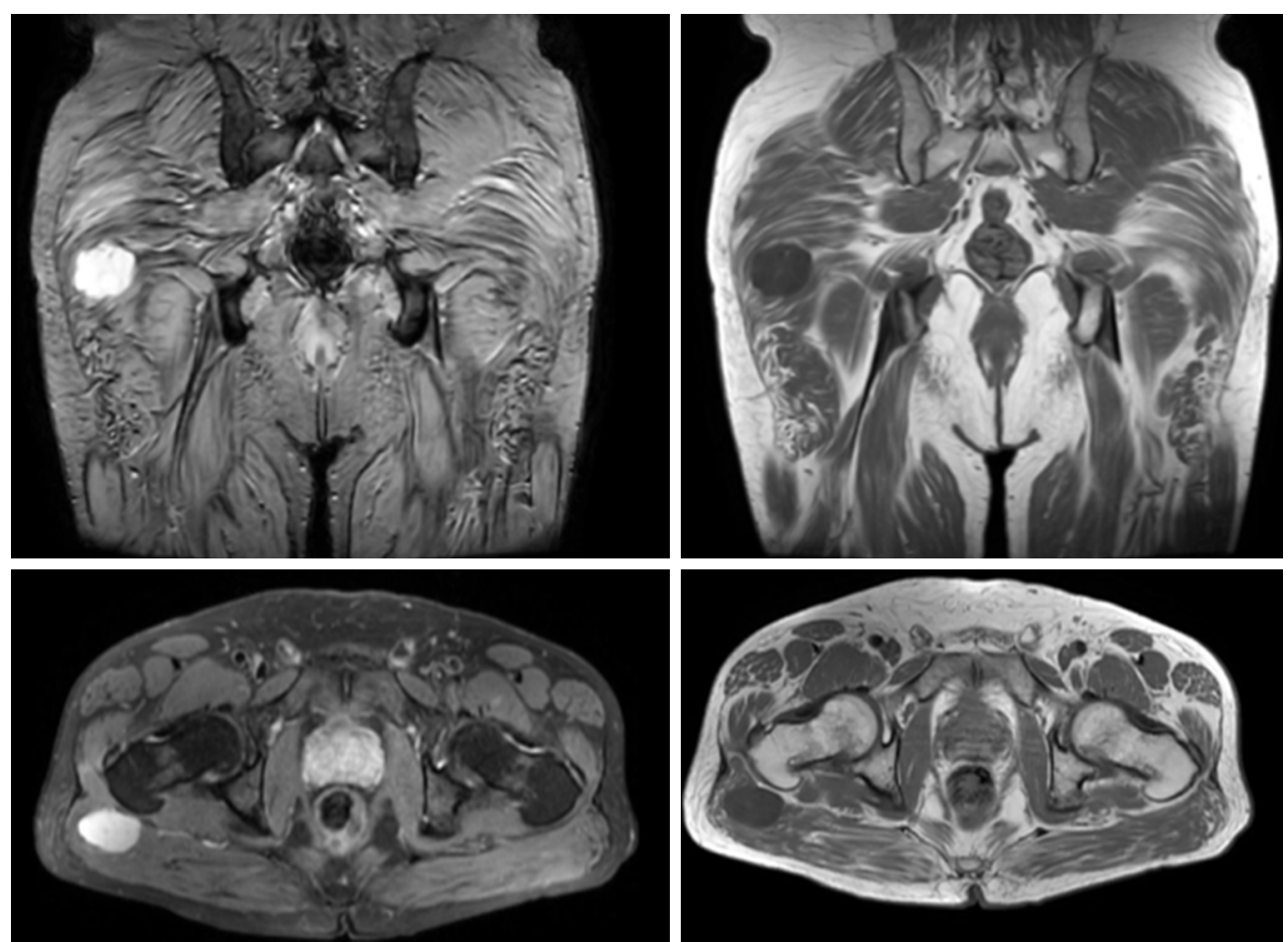

Figure 1. Magnetic resonance imaging showing a well-circumscribed, septated, $4.5 \times 4-\mathrm{cm}$ in size mass with cystic components.

tissues. On MRI, a well-circumscribed, septated, $4.5 \times 4-\mathrm{cm}$ mass with cystic components located in the gluteus maximus muscle was identified (Figure 1). Fine-needle aspiration biopsy was performed and histopathological examination revealed the diagnosis of an intramuscular myxoma. The tumor composed of cytologically bland spindled and stellate-shaped cells separated by widely abundant mucoid material. The cells had small hy perchromatic nuclei and scanty

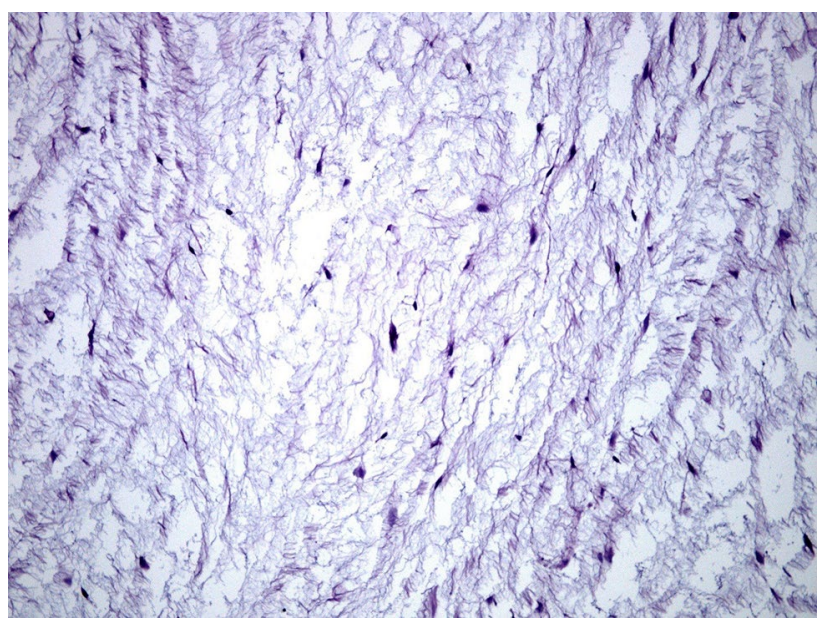

Figure 2. The cells with small hyperchromatic nucleus having no cytological atypia $(H-E, \times 400)$. cytoplasm did not have mitotic figure. Tumor cells were immunohistochemically positive for vimentin and CD34, but negative for S-100 protein (Figure 2).

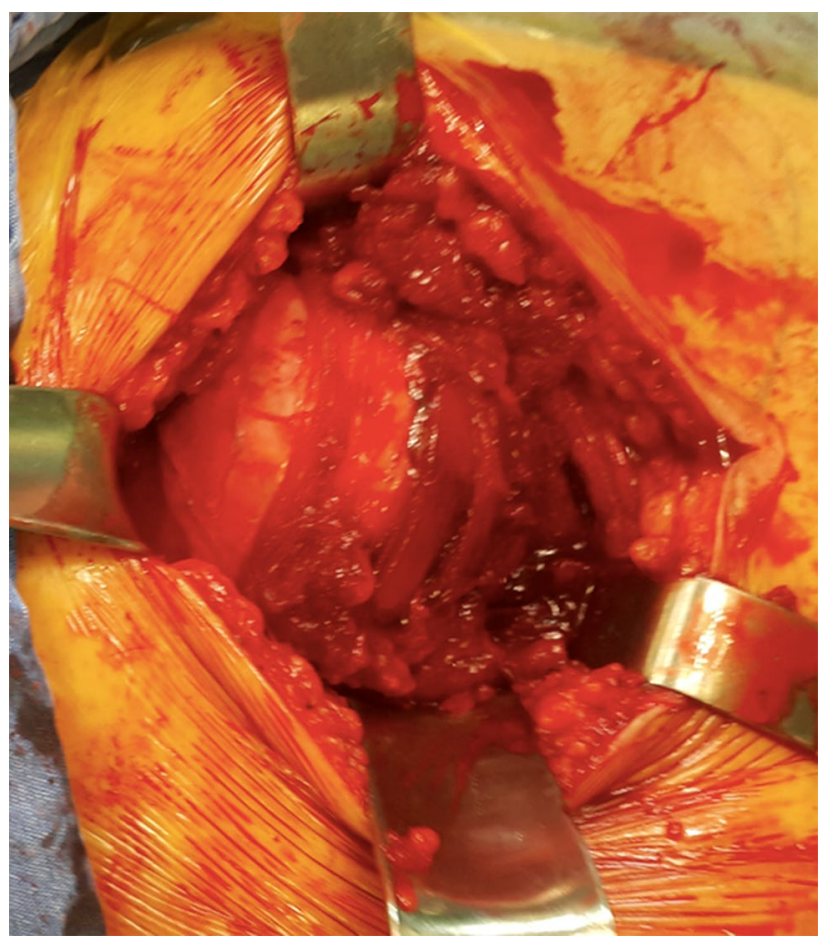

Figure 3. Intraoperative appearance of the lesion. 


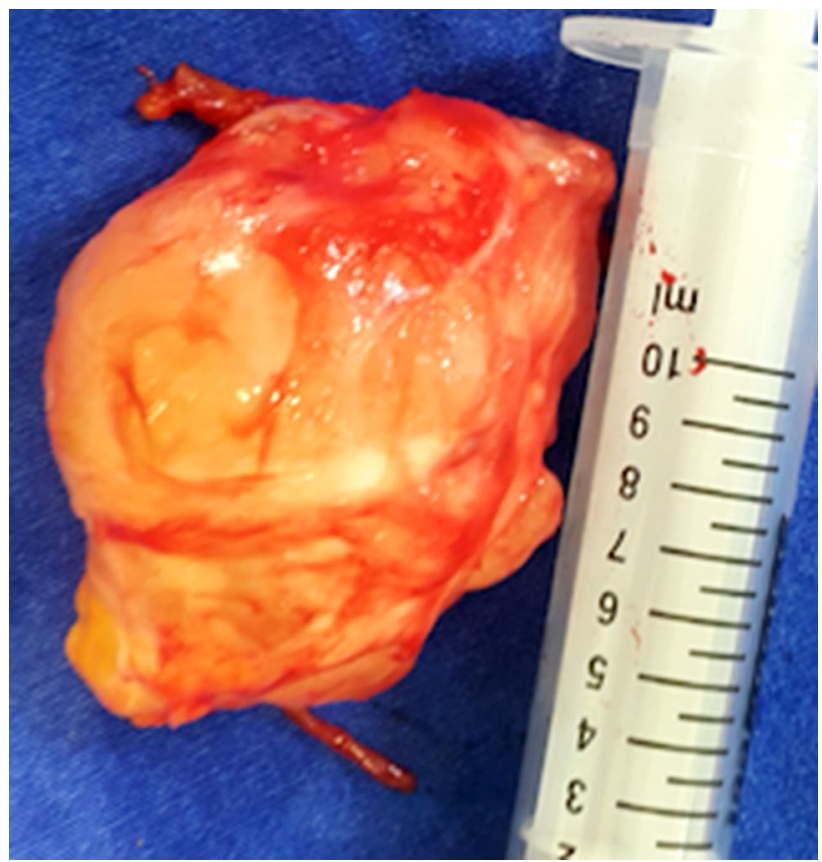

Figure 4. The lesion after local excision.

Surgical removal was planned and the mass was completely excised under spinal anesthesia. The tumor appeared to be an encapsulated gelatinous mass, encased within the muscle. It was easily separated from the muscle (Figures 3 and 4). There was no recurrence one year after the operation.

The patient was informed that data from the case would be submitted for publication and gave their consent.

\section{DISCUSSION}

In 1863 , Virchow ${ }^{[5]}$ used the term myxoma to describe a lesion that histologically resembled the umbilical cord. In 1948, Stout ${ }^{[3]}$ studied 142 cases and outlined the diagnostic criteria, and defined myxoma. Most of those cases were in the heart and only 3\% of the tumors were found to be intramuscular. In 1965, Enzinger ${ }^{[6]}$ reported that intramuscular myxoma cases were approximately $17 \%$ of the myxomas. He reported intramuscular myxoma as a distinct subtype of myxomas. Intramuscular myxoma is a slow-growing tumor and usually presents as a painless mass that may exhibit symptoms due to the compression of surrounding structures. Intramuscular myxomas are firm, painless, palpable, mobile, slowly growing mass, and sometimes fluctuant. Symptoms are due to the compression of surrounding structures. Patients usually complain of a round-shaped, painless, slowly growing mass that exists from a few months to several years. There is often a trauma history in the past.
In case of intramuscular myxomas, the Mazabraud syndrome should be considered. It is a rare disorder characterized by the association of fibrous dysplasia and one or multiple intramuscular myxomas. ${ }^{[7]}$ Clinical diagnosis is difficult without biopsy or tumor excision and microscopic examination. Radiographs are usually normal. The MRI is the ideal imaging method for preoperative identification of intramuscular myxoma detected as a well-defined ovoid mass exhibiting low T1-weighted and increased T2-weighted signal. Contrast-enhanced MRI studies demonstrate heterogeneous internal enhancement and/or peripheral enhancement with occasional fine internal septa. The MRI may also show surrounding fat rim or cap and surrounding muscle edema. ${ }^{[8]}$

Macroscopically, the tumor usually has an oval shape and shows a well-circumscribed appearance; however, the fibrous capsule is usually incomplete and infiltrates the adjacent musculature. When the cut open the tumor has usually a glistering gray-white appearance and contains a gelatinous material and cyst filled with fluid inside the mass. Histologically, intramuscular myxoma is characterized as a hypocellular tumor composed of spindle-shaped and stellate cells embedded in an abundant myxoid stroma. Some myxomas may show focal areas of hypercellularity. Vascular structures are sparse or absent. There is no nuclear atypia, necrosis, and prominent mitotic figures in intramuscular myxoma. In immunohistochemical studies, intramuscular myxoma cells stain positively for vimentin and show variable staining for CD34 and actin; immunostain for S-100 protein is typically negative. The tumor is to be differentiated from sarcomas, metastasis, and other benign intramuscular tumors such as lipoma, hemangioma, hematoma, desmoid tumor. ${ }^{[9]}$ Due to the recent discovery of $G$ protein Gs alpha (GNAS1) mutations, specificity has increased in intramuscular myxomas. These mutations have been identified in intramuscular myxoma with and without fibrous dysplasia. Willems et al. ${ }^{[10]}$ reported that GNAS1 mutation analysis can be helpful to distinguish intramuscular myxoma from low-grade myxofibrosarcoma in selected cases.

In conclusion, the recommended treatment for intramuscular myxoma is excision which can be expected to be curative, as in the present case. In the presence of persistent pain and palpable mass after having continuous intramuscular injections in the same region, intramuscular myxomas should be considered in differential diagnosis. 


\section{Declaration of conflicting interests}

The authors declared no conflicts of interest with respect to the authorship and/or publication of this article.

\section{Funding}

The authors received no financial support for the research and/or authorship of this article.

\section{REFERENCES}

1. Heymans O, Gebhart M, Alexiou J, de Saint Aubain $\mathrm{N}$, Larsimont D. Intramuscular myxoma. Acta Chir Belg 1998;98:120-2.

2. Murphey MD, McRae GA, Fanburg-Smith JC, Temple HT, Levine AM, Aboulafia AJ. Imaging of soft-tissue myxoma with emphasis on CT and MR and comparison of radiologic and pathologic findings. Radiology 2002;225:215-24.

3. Stout AP. Myxoma, the tumor of primitive mesenchyme. Ann Surg 1948;127:706-19.

4. Costamagna D, Erra S, Durando R. Intramuscular myxoma of the deltoid muscle: Report of a case. BMJ Case Rep 2009;2009:bcr08.2008.0678.
5. Virchow R. Intramuscular myxoma of the cervical paraspinal muscle. In: Cellular Pathology as Based upon Physiological and Pathological Histology. Philadelphia: JB Lippincott; 1863. p. 525-6.

6. Enzinger FM. Intramuscular myxoma; a review and followup study of 34 cases. Am J Clin Pathol 1965;43:104-13.

7. Biazzo A, Di Bernardo A, Parafioriti A, Confalonieri N. Mazabraud syndrome associated with McCune-Albright syndrome: A case report and review of the literature. Acta Biomed 2017;88:198-200.

8. Nishio J, Naito M. FDG PET/CT and MR imaging of intramuscular myxoma in the gluteus maximus. World J Surg Oncol 2012;10:132.

9. Özbek N, Danaci M, Okumus B, Gürsel B, Gokce S, Dabak $\mathrm{N}$, et al. Recurrent intramuscular myxoma: Review of the literature, diagnosis and treatment options. Turk J Cancer 2006;36:75-8.

10. Willems SM, Mohseny AB, Balog C, Sewrajsing R, Briairede Bruijn IH, Knijnenburg J, et al. Cellular/intramuscular myxoma and grade I myxofibrosarcoma are characterized by distinct genetic alterations and specific composition of their extracellular matrix. J Cell Mol Med 2009;13:1291-301. 